Article

\title{
Visual-Based Positioning of Aerial Maintenance Platforms on Overhead Transmission Lines
}

\author{
Oswaldo Menéndez ${ }^{+}$(D), Marcelo Pérez ${ }^{+}$(D) and Fernando Auat Cheein *, + (D) \\ Department of Electronic Engineering, Universidad Técnica Federico Santa María, Valparaíso 2390123, Chile; \\ oswaldo.menendez.5@sansano.usm.cl (O.M.); marcelo.perez@usm.cl (M.P.) \\ * Correspondence: fernando.auat@usm.cl; Tel.: +56-32-265-2617 \\ + These authors contributed equally to this work.
}

Received: 12 November 2018; Accepted: 6 December 2018; Published: 4 January 2019

\begin{abstract}
Unmanned aerial vehicles (UAVs) are an emerging and promising alternative for monitoring of transmission lines in terms of flexibility, complexity, working speed, and cost. One of the main challenges is to enable UAVs to become as autonomous as possible. A vital component toward this direction is the robust and accurate estimation of the UAV placement with respect to the transmission grid. This work faces this challenge by developing a transmission line autonomous tracking system, which allows the placement of a commercial drone over a transmission grid using a monocular camera. This feature provides accurate positioning for the vehicle even where the Global navigation satellite system (GNSS) signal is denied, enabling to report the status of transmission lines, at any time. The system isolates transmission grid conductors in each acquired RGB-image using an image-processing algorithm based on Hough transform, morphological operations, and Gabor filters. With this information, the system computes the location of the UAV using a geometric approach that relates transmission lines building parameter and optical geometry. However, it has the problem of gradual error accumulation when the drone moves. In this regards, the estimated position of the drone is computed by the maximum likelihood estimation (MLE) by the position information estimated by visual-system, the inertial measurement unit (IMU) and GNSS. The proposed positioning system showed an efficiency of $91.44 \%$ in field experimentation in the extraction of transmission conductor, with a root mean square the error of $0.18 \mathrm{~m}$ in the UAV localization.
\end{abstract}

Keywords: robotics; robot vision systems; image motion analysis; transmission line inspection

\section{Introduction}

Inspection of power system assets-including conductors, protection systems, towers, transformers and other devices-plays an important role in addressing the growing need for sustainable energy worldwide. High-voltage overhead transmission lines are essential assets in power systems that require careful and frequent monitoring to reduce probable failures related to environmental, operational, animal or human threats [1,2] and to ensure their proper operation. However, monitoring process is often neglected or shelved due to more pressing priorities, high deployment costs or industrial policies, which brings hardship to both unprepared businesses and society at large [3,4].

Within this context, the development of machinery based on autonomous robots, dedicated systems and intelligent machines, helps face the increasingly complex challenges within a rapidly expanding power industry [5], ensuring an efficient, cost-effective and safe maintenance process [6]. Currently, robotics presents itself as an affordable alternative to perform maintenance tasks in power systems, due to its technical characteristics, its outstanding performance to improve several industrial process [7] and its adaptability to different and hostile environments such as: electrical substations [8], high voltage overhead transmission lines [9] or power plants [10]. 
Several mechanisms have been developed to perform inspection tasks in an energized transmission grid. Among the most noteworthy initiatives are brachiating robots, unmanned aerial vehicles and ground vehicles [9], each with its own advantages, disadvantages and characteristics, as summarized in Table 1. Unmanned aerial vehicles (UAV) have reached technological summit during the last decade [11], due to their top-quality technical and economic performance. During this period of time, UAVs evolved from a niche market of small scale applications to a common inspection, treatment and surveillance platform of electric equipment mounted on transmission grids. This technology can be used to perform inspection tasks of equipment under hazardous conditions or access restrictions, due to it navigation is only affected by Chilean Flight Regulation-DAN 151, where the guidelines to perform the UAV flight over high voltage overhead transmission lines is summarized.

Inspection tasks include methods in which a dataset provided by a huge number of different sensors is interpreted by computer analysis to identify specific conditions or certain types of defects [9]. The variety of sensor needs is illustrated in Figure 1. These sensors can be mounted in aerial platforms in order to increase the flexibility, to reduce the inspection time and to avoid operational risks [12]. The use of UAVs has become increasingly popular for visual industry inspection; the systems are equipped with different cameras, which provide image representations in visual, infrared or ultraviolet spectral bands and each of these bands has advantages for detecting a huge number of damages or defects $[9,13]$. Of note among the main applications of visual inspection are to evaluate the condition of structural components such as wires [14], conductors [15], and towers and to detect contamination or physical damages on power insulators [16]. In addition, visual inspection work is highly used to detect encroachment on the ground or near the tower structure. In off-line applications, the UAV can store several images of the transmission grid, which are analyzed to detect patterns that would indicate fatigue, cracks [17], rust, corrosion [18] or other damages. In addition, the surveillance of transmission lines against terrorist attacks can be developed by UAVs [19].

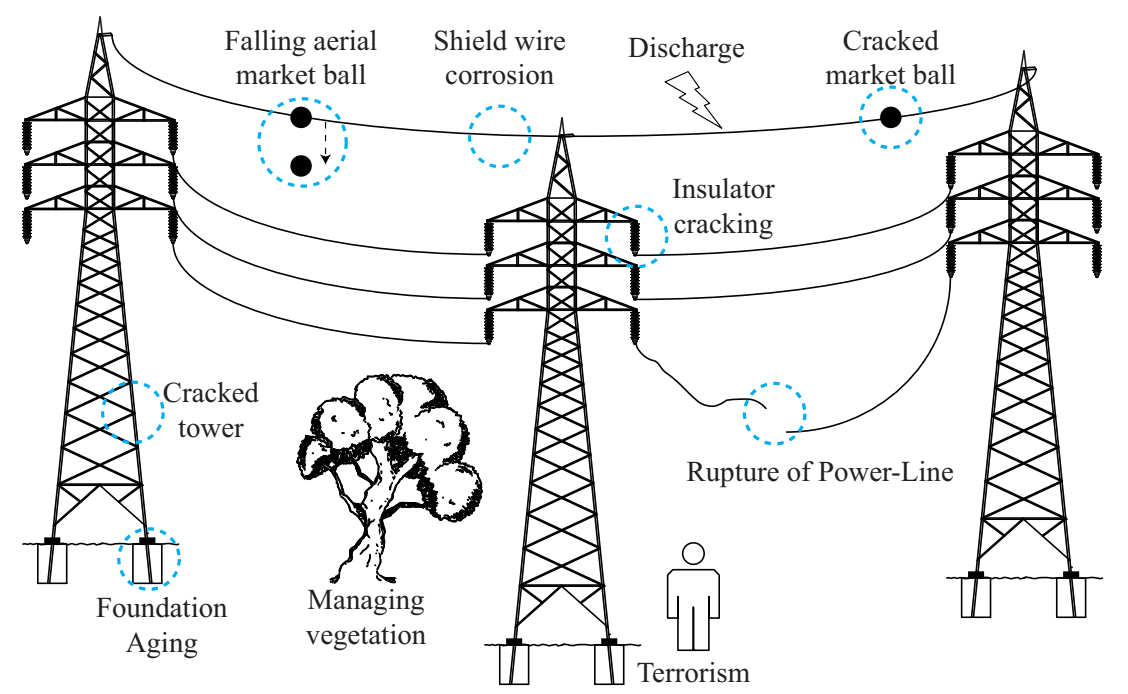

Figure 1. The main threats in transmission lines and their impact.

The thermal analysis provides relevant information about the status of different mechanisms mounted on a transmission grid [20]. Currently, this process is carried out with a wide range of real-time monitoring devices that determine the dynamic thermal rating of a transmission grid [20-22] and are mounted on the line. The use of UAVs, coupled with infrared imaging could be used to autonomously detect failing components or insulator leakage currents [23]. On the other hand, ultraviolet cameras could be used to detect sources of corona and arcing [24] that indicate insulator hardware failure and can cause damage to other components [25].

Although cameras are the most used sensors in UAV surveys, there are other sensors based on different technologies (e.g., vibrational sensing, leakage current sensing), which can be used to identify 
a wide variety of phenomena in transmission grid devices [26]. Vibration sensors are highly used to detect different phenomena such as tower tampering, avian nesting activity, lightning strikes, damages in ceramic insulators and damages in tower foundation. An indicator of the insulator contamination level can be used to detect leakage currents [12,27]. However, these sensors cannot be directly mounted on robotic platforms because they must be in contact with the structure. In this context, UAVs are provided with a data acquisition system that allows them to collect the data from remote sensors.

Table 1. Comparison of three main robotic platforms used to perform inspection work in transmission lines.

\begin{tabular}{cccc}
\hline Type of Robot & Ground Vehicles & Brachiating Robots & Unmanned Aerial Vehicles \\
\hline $\begin{array}{c}\text { Payload } \\
\text { Restriction }\end{array}$ & Low & Medium & High \\
\hline $\begin{array}{c}\text { Navigation } \\
\text { Restriction }\end{array}$ & $\begin{array}{c}\text { Ground } \\
\text { accessibility. }\end{array}$ & $\begin{array}{c}\text { Crossing } \\
\text { obstacles. }\end{array}$ & $\begin{array}{c}\text { Chilean flight } \\
\text { regulation. }\end{array}$ \\
\hline Autonomy & High & Medium & Low \\
\hline $\begin{array}{c}\text { Maintenance } \\
\text { work }\end{array}$ & Yes & $\begin{array}{c}\text { Temporary } \\
\text { repairs. }\end{array}$ & No \\
\hline $\begin{array}{c}\text { Development } \\
\text { cost }\end{array}$ & Very high & High & Low \\
\hline $\begin{array}{c}\text { Industrial } \\
\text { prototypes }\end{array}$ & $\begin{array}{c}\text { LineMaster [28] } \\
\text { Elevator IV [29] }\end{array}$ & $\begin{array}{c}\text { LineROVer [31] } \\
\text { Expliner [32] } \\
\text { LineScout [33] }\end{array}$ & $\begin{array}{c}\text { AIBOT-6 [34] } \\
\text { UAV-Borne [35] }\end{array}$ \\
\hline
\end{tabular}

Nevertheless, technology constraints related to the payload and autonomy could affect critical processes such as navigation and localization, restricting the use of these platforms. A navigation system based on global navigation satellite system (GNSS) is currently the most adopted sensing mode to locate aerial platforms over different industrial environments [36]. In an electrical environment, however, the use of GNSS is limited because it has size and weight constraints of aerial platforms and sensors; it can be affected by electromagnetic interference; it cannot operate in cluttered urban areas; and it is not reliable at low altitudes and suffers from satellite signal cuts [37].

In this context, several works are focused on overcoming positioning issues. Piloted airborne platforms equipped with artificial vision systems are an alternative for solving many problems related to UAVs $[11,38]$. Capturing remote sensing data from satellites is also a possible solution, but it has several restrictions related to the unfavorable revisit time and spatial and spectral resolutions [39]. An artificial vision system mounted in an UAV has the potential to fill this gap, by providing a cheap and flexible way to gather the transmission line information while carrying out the inspection process $[40,41]$. The images are processed with the purpose of detecting faults [42] and vegetation [43] or to extract power-lines for analysis [44,45]. Power wires can be detected using a line segment detection algorithm [46] or Hough transform with parallel constraint [47]. Visual inspection is a line with great application for aerial robots, since it offers the feature of capturing images in dangerous areas with difficult access [48,49].

This work describes the development and implementation of a transmission lines detection system, focusing on autonomous drone flight. The system extracts geometric patterns associated to the transmission line design andl based on such patterns, it is possible to obtain the position and attitude of the aerial platform, allowing to locate the drone over an electric network without using GNSS receiver. A novel two-stage visual navigation algorithm is proposed which can be mounted on any manual, teleoperated or robotic platform due to its flexibility. The transmission detection is an important action to guarantee the positioning of the platform. In this context, the algorithm in its first part applies image processing tools and develops a cropped power grid image, isolating the power-lines from the rest of the environment. An important challenge is related to perspective distortion, the system addresses 
this issue using texturing filtering and perspective correction algorithm. In addition, texturing filtering can simultaneously remove the background noise of power lines as well as generate edge maps. The system applies Hough transform to edge maps to detect straight lines in images that can be related to power-lines. Finally, the system determines power-lines by taking advantage of the regular characteristics of power lines. Additionally, the system uses the prior information of platform position in order to reduce the computational cost and to improve the power line detection. The second stage determines the distance to wires and the robot position using Bayesian methods. The system merges sensor information (IMU and GNSS) with visual information provided by our system using Maximum Likelihood Estimation. This information would allow the equidistant flight over the transmission lines.

\section{Material and Methods}

The visual-based positioning system proposed in this work allows to locate and maneuver a commercial drone over a transmission grid. As shown in Figure 2, in the proposed approach the UAV acquires visual images of the conductors using a monocular camera and sent each image to a ground station. The system position is estimated and the navigation commands are sent back to the UAV in order to maintain the position respective to the transmission lines.

1. A commercial UAV is positioned over a transmission grid, controlled by an operator. The distance from the UAV to conductors varies depending on the safety, lighting conditions and camera characteristics, requiring at least $1 \mathrm{~m}$ between the conductors and the vehicle.

2. The exteroceptive information is acquired with a monocular camera, which is mounted at bottom of the UAV.

3. To avoid the direct incidence of sunlight, a two-axis hand-held gimbal changes the camera vision point to avoid sensor saturation.

4. The positioning process computes the placement of the camera based on conductors geometric design. In addition, the system is capable of storing a compressed image, with geo-referenced information as a back up and as support to a future inspection work.

5. The current version for the positioning system only performs the flight over three-phase transmission grids with conductors approximating straight lines without interruption. Its operating system is flexible in order to add other features. Transmission lines with other distribution can be detected using Hough transform variations since the system is based on the geometric pattern.

6. A navigation strategy consists of two stages: (i) power-line detection; and (ii) electrical tower detection. Our visual positioning system is focused on the first goal. Therefore, the system is disabled when the UAV is near an electrical tower, changing to manual mode. The maximum speed is $75 \frac{\mathrm{km}}{\mathrm{h}}$. However, we limit this velocity to $25 \mathrm{kph}$ to increase the probability of power-lines detection and to reduce blurring effects.

7. The drone has a flight autonomy of $30 \mathrm{~min}$ (empirically determined). If the drone detects a low energy level of its batteries, the vehicle selects between two flight modes: land (attempts to bring the UAV straight down) or return to the launch (the UAV navigates from its current position to hover above the home position), depending on the distance to starting point.

8. The drone performs inspection tasks along a length of about $10 \mathrm{~km}$ in $1 \mathrm{~h}$ intervals (Battery charging time).

9. The proposed drone operates in a dry ambient, ideally at a standard environment of $20{ }^{\circ} \mathrm{C}$ and $50 \%$ humidity. However, the aerial platform can also be placed in a rugged ambient, whose temperature is not less than $5{ }^{\circ} \mathrm{C}$ or more than $40^{\circ} \mathrm{C}$ and whose humidity is not more than $80 \%$. The apparatus cannot be directly exposed to rain and it is capable of facing wind gusts of up to $10 \frac{\mathrm{km}}{\mathrm{h}}$. 


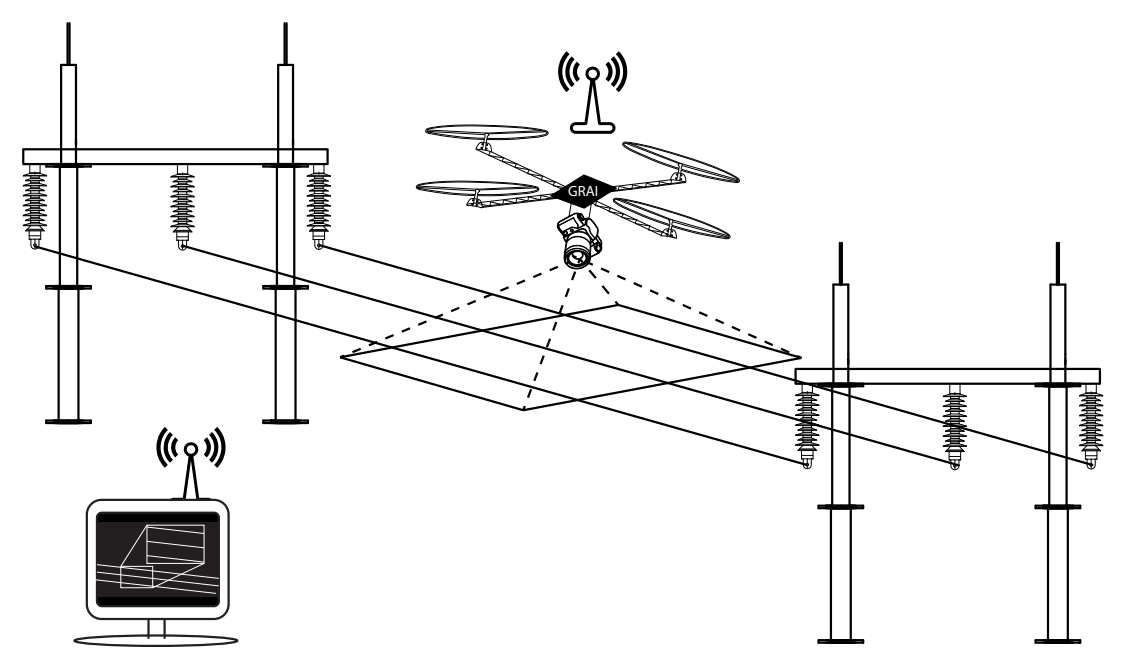

Figure 2. UAV inspection in transmission lines.

\section{Hardware Design}

A drone with six rotors was designed, implemented, and tested for the autonomous inspection of transmission lines. The robotic platform can be described in general terms as follows:

- The drone deployed in real applications has a flight controller (Type Erle Brain 2 with a $900 \mathrm{MHz}$ quad-core ARM Cortex-A7 CPU processor), which has a flight control unit (a computer that provides basic flight controls) and a companion computer (computational system in charge of image processing and image broadcasting). Additionally, the controller has an inertial measurement unit (IMU), an integrated altimeter and an embedded Kalman Filter for the treatment of signals. The UAV also has a GNSS antenna with an absolute error of $1 \mathrm{~m}$.

- Visual data are acquired with the SJ4000 Turnigy HD ActionCam 1080P Full HD video camera. According to the manufacturer, the visual camera in TV mode has a resolution of $1920 \times 1080$ pixels.

- The monocular camera has been previously calibrated to find the focal point and to estimate its parameters. Additionally, the camera is aligned with a gimbal that compensates the fast dynamic rotation of the hexacopter and controls the image plane to stay horizontal and parallel to power-lines. This process is essential for smooth target tracking in the image. The visual information is sent to a computational device that is in charge of higher-level behaviors, in an embedded form, such as the image processing and image broadcasting.

- The information extracted is stored locally in a 16 GB internal memory and sent as a data packet at regular intervals to a companion computer to prevent problems occurrence. To perform this process, the drone is equipped with a communication system based on a transmitter/receiver $433 \mathrm{MHz}$ and WIFI connection employed for telemetry operations, and transmitter/receiver $5.8 \mathrm{GHz}$ employed for image broadcasting.

- The UAV works with the Robot Operating System (ROS-Indigo) [50], adapted to the specifications of this problem.

The general scheme of the sensory and processing system embedded in the UAV is shown in Figure 3. 


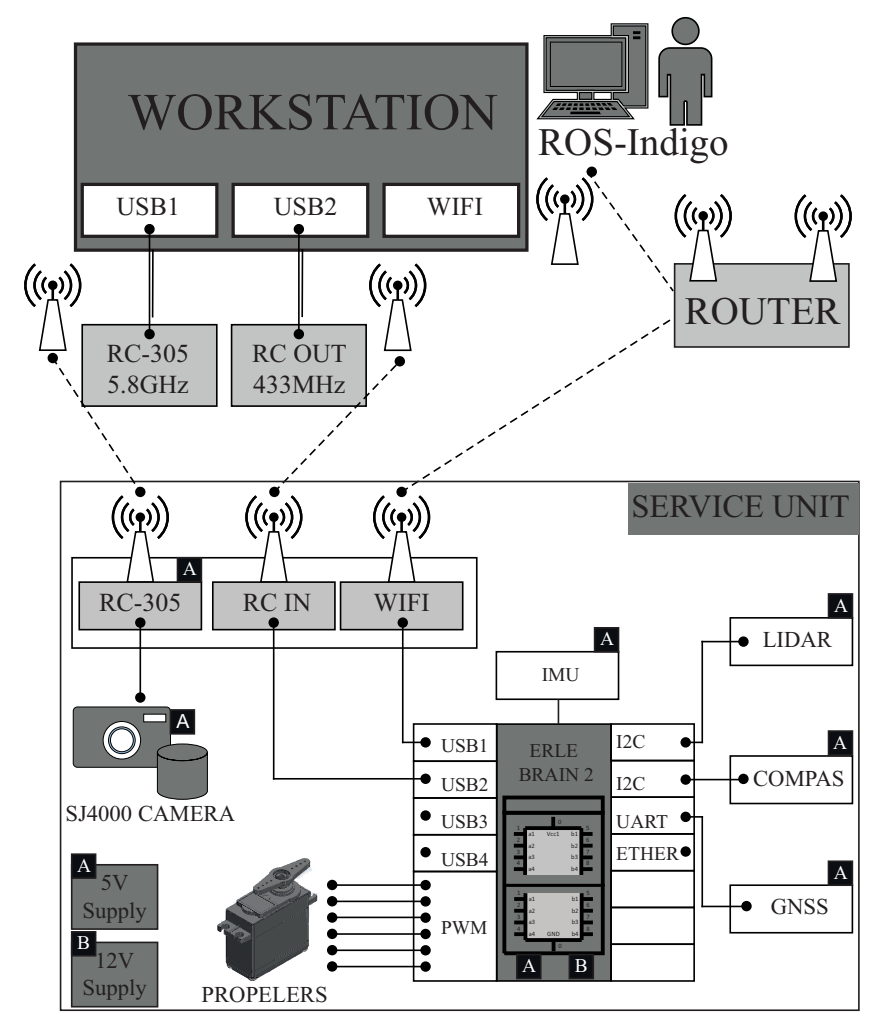

Figure 3. General diagram of the hardware developed in the robotic platform.

\section{Visual-Based Positioning System}

A mathematical formulation of the proposed positioning algorithm is developed in this section. The algorithm consists of three stages: image pre-processing, transmission line detection and spatial positioning of the $U A V$, as summarized in Figure 4.

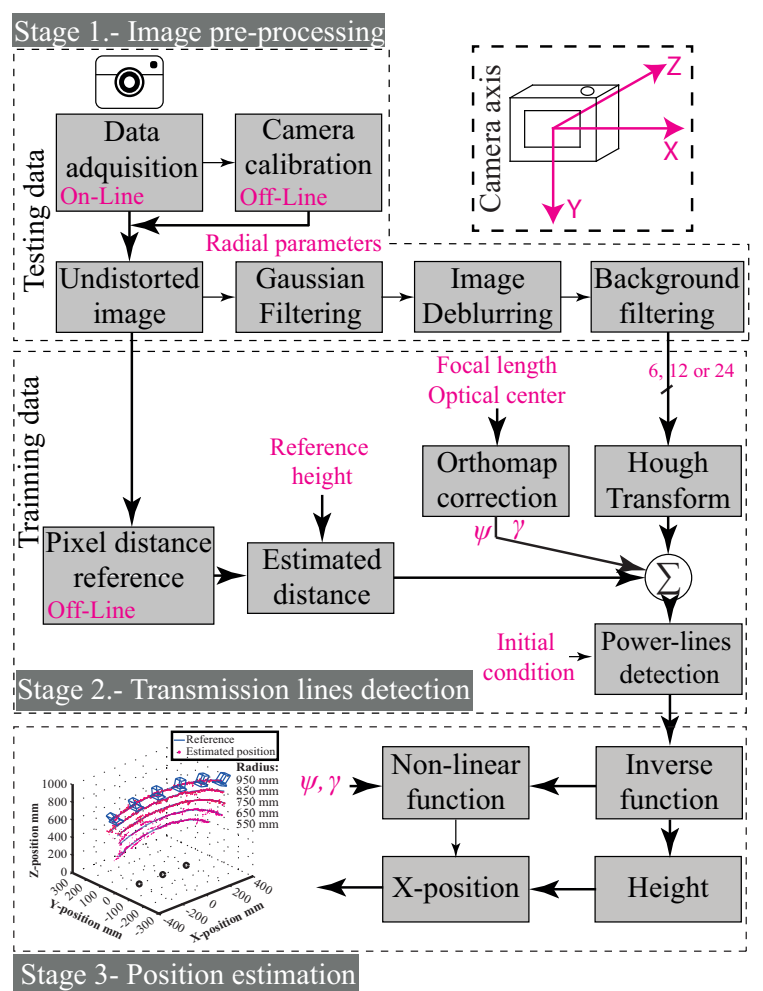

Figure 4. Processing architecture of the power-lines detection system. 


\subsection{Image Pre-Processing}

Lens distortion and noise directly disturb acquired images, decreasing the detection of power conductors in the images. Therefore, the system must be capable of filtering out these phenomena to measure the separation between conductors in world units and to determine the drone's location in the work-space. With this aim, traditional camera calibration method estimates the intrinsic and extrinsic parameters and distortion coefficients, while the digital signal processing algorithms-presented herein-reduce the noise, correct image defects and remove blurry distortion, guaranteeing the transmission lines detection [51].

On the other hand, each pre-processed image has several extra objects, which are not related to the transmission grid. These objects from the scene must be attenuated or removed; otherwise, the system must intensify the pixels related to the transmission lines to isolate the three-phase transmission lines from the image background. With this goal, the image is subjected to anisotropic Gaussian filtering [52], which improves the texture quality of transmission lines and removes irrelevant data, regardless of line location in the image, as well as its length and slope.

The filter bank consists of an edge filter, at 6,12 or 24 orientations and one scale $\left(\sigma_{x}, \sigma_{y}\right)=(1,3)$. The orientations are selected based on the computational time and the image size. The resulting image in each filtering process is filter with the Sobel detector to intensify the edges and to obtain a binarized version with the probable power wires. The system delivers a tensor with 6, 12 or 24 binarized images.

A fixed pattern in the transmission grid, mainly on its conductors, is the symmetric geometric design. The system looks for patterns with similar characteristics to conductor in each binarized image. In this work, the UAV flies over transmission grids with conductors approximating a straight line, without interruption. Hough transform can be successfully used to solve this problem, since this method identifies the section of the binarized image where high probability of finding straight lines exists [53].

The Hough transform defines a straight line as a co-linear set of points, mapping $\mathbb{R}^{2}$ into the function space of sinusoidal functions defined by:

$$
f:(x, y) \rightarrow \rho=x \cos (\theta)+y \sin (\theta)
$$

where $\rho$ and $\theta$ are the perpendicular distance of the line $\ell_{i}$ to the center of the coordinates and the angle between the normal of this line and $x$-axis, respectively.

In this context, the algorithm returns a dataset with all lines $\left(\rho_{i}\right.$ and $\left.\theta_{i}\right)$ that meet the previous specifications related to the geometric design of the transmission grid for each binarized image. Then, all measurements related to same line are merged using Fuzzy C-Means algorithm.

\subsection{Transmission Line Detection}

Transmission lines detector uses the geometric design and uniformity of transmission lines to establish the power wires in each image. At this stage, the purpose is to find a set with three or more straight lines that fulfill the parallelism and equidistance of transmission lines. Using the parameters $\rho$ (the distance between the line and the origin) and $\tan (\theta)$ (slope) that are provided by Hough transform, it is possible to prove these conditions. However, topographic relief and camera tilt disturb the equidistant line recognition process, as shown in Figure 5a. These negative events are corrected using an image orthorectification process.

The image orthorectification process corrects the adverse effects using the geometric relation between different angles and known distances; this relation is displayed in Figure 5b, where each parameter is described as follows:

- $\quad \alpha_{1}$ and $\alpha_{2}$ are the angles between the real points of power-lines and focal point.

- $\quad \gamma$ is the draft angle of the camera around $x$-axis.

- $\quad \psi$ is the field of view (FOV). 
- $\quad d_{1}$ and $d_{2}$ are the distorted distances measured in pixels between power-line in the center and power-line left and right, respectively.

- $\quad d, d^{\prime}{ }_{1}$ and $d^{\prime}{ }_{2}$ are the real distances measured in pixels between transmission line phases, when the camera plane is parallel to power-lines plane.

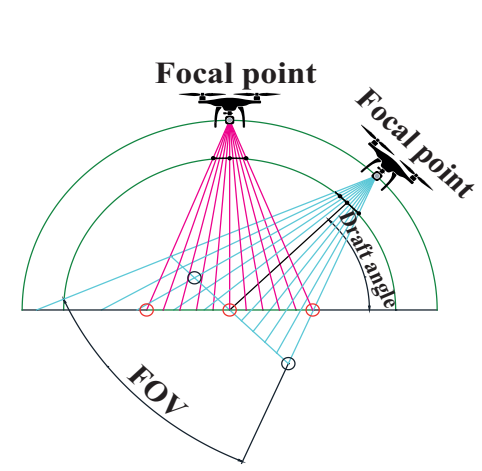

(a)

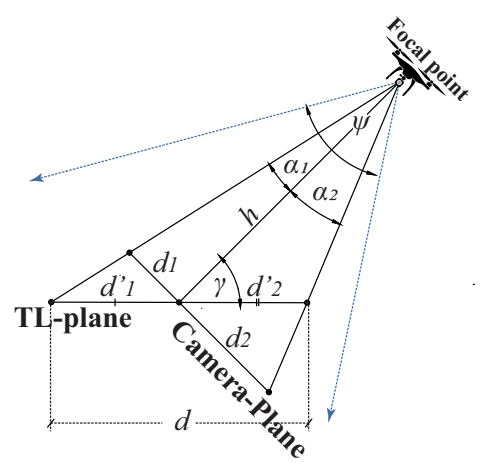

(b)

Figure 5. Analysis of the camera attitude -including the main angles for mathematical expressions: (a) effect of the topographic relief and the camera tilt in the acquisition of images; and (b) necessary angles for orthogonal correction.

Using geometry, it is possible to solve this problem and to compute the distance $d^{\prime}{ }_{1}$ as a function of $d_{1}$ :

$$
d_{1}^{\prime}=d_{1} \times\left(\frac{\cos (\gamma)}{\tan \left(\gamma-\alpha_{1}\right)}+\sin (\gamma)\right)
$$

and $d^{\prime}{ }_{2}$ as function of $d_{2}$ :

$$
d_{2}^{\prime}=d_{2} \times\left(\frac{\cos (\gamma)}{\tan \left(\gamma+\alpha_{2}\right)}+\sin (\gamma)\right)
$$

The system acquires several images at fixed height $h_{r e f}$ above the transmission lines to determine the relation between image units and world units. In this work, power wires were manually extracted in each image, and the separation between them was directly measured in the image. The estimated reference distance $\hat{d}$ is determined using a consistent estimator of the mean. This will help to determine the measurement of the separation between power wires as well as the drone position, as shown in the next section.

\subsection{Estimation of the Position Based on Visual Data}

The estimated height is determined by applying an inverse linear function that relates the measured distance, the reference distance and reference height to the camera height. The height is defined as:

$$
\hat{h}=\frac{h_{r e f} \times \hat{d}}{d^{\prime}{ }_{1}+d^{\prime}{ }_{2}} \times \sin (\gamma) ;
$$

where $\hat{h}$ is the estimated drone height to transmission lines, $h_{r e f}$ is the reference height and $\hat{d}$ is the reference distance in the image in number of pixels

As explained above, during off-line mode the reference separation $\hat{d}$ is established. Hence, it is possible to compute the $\mathrm{x}$-position and y-position of the camera in relation to the center-line transmission system as:

$$
\begin{aligned}
& \hat{x}=\frac{\hat{h}}{\tan (\gamma-\alpha)} \times \cos (\delta) \\
& \hat{y}=\frac{\hat{h}}{\tan (\gamma-\alpha)} \times \sin (\delta)
\end{aligned}
$$


where $\hat{x}$ and $\hat{y}$ are the estimated $\mathrm{x}$-position and y-position of the camera in relation to the center power conductor, respectively and $\delta$ is the rotation angle of the camera around the z-axis.

Visual-based positioning cannot be applied if the transmission lines are not visible since any outcome can be returned by the system under such circumstances. However, the robotic platform has two additional sensors (IMU and GNSS receiver), with different probability density functions $(p d f)$, estimating the spatial positioning of the UAV. This information can be used with any Bayesian method to estimate the system placement. With this aim, in this work was implemented the maximum likelihood estimation [54], associating a Gaussian probability density function to each sensor. The corresponding analysis presented in Equations (7) and (8) reveals that the new estimation $\hat{\theta}$ is a weighted average and the new uncertainty $\sigma_{\theta}^{2}$ can be generated through addition of the reciprocals:

$$
\begin{gathered}
\hat{\theta}=\frac{z_{1} \sigma_{2}^{2} \sigma_{3}^{2}+z_{2} \sigma_{1}^{2} \sigma_{3}^{2}+z_{3} \sigma_{1}^{2} \sigma_{2}^{2}}{\sigma_{1}^{2} \sigma_{2}^{2}+\sigma_{2}^{2} \sigma_{3}^{2}+\sigma_{1}^{2} \sigma_{3}^{2}} \\
\sigma_{\theta}^{2}=\frac{\sigma_{1}^{2} \sigma_{2}^{2} \sigma_{3}^{2}}{\sigma_{1}^{2} \sigma_{2}^{2}+\sigma_{2}^{2} \sigma_{3}^{2}+\sigma_{3}^{2} \sigma_{1}{ }^{2}} \\
\sigma_{\theta}{ }^{-2}=\sigma_{1}{ }^{-2}+\sigma_{2}{ }^{-2}+\sigma_{3}{ }^{-2}
\end{gathered}
$$

where $z_{i}$ is the measurement of each sensor and $\sigma_{i}^{2}$ denotes its variance (in this work, the parameters $z_{1}$ and $\sigma_{1}^{2}$ are related to IMU, $z_{2}$ and $\sigma_{2}^{2}$ are related to GNSS and $z_{3}$ and $\sigma_{1}{ }^{3}$ are related to our system).

\section{Results}

A set of experiments were conducted in laboratory, simulation and field environments. The proposed approach was simulated using the GAZEBO software [55] and linking this with ROS [50] and MATLAB [56]. Finally, field tests in a real transmission grid, located in the township of Casablanca, in the Valparaiso Region, Chile were carried out.

\subsection{Laboratory Validation}

A scale model 1:8 of a three-phase distribution system with power-lines, approximating a straight line and without interruption was used in the laboratory validation. The model was wrapped with camouflage at the bottom to simulate the different objects which could be found in a transmission grid environment. The UAV movement was simulated by a KUKA robotic arm model KR-6.

Laboratory experiments were conducted in the Centro Integrado de Manofactura y Automatización (CIMA) at the Universidad Técnica Federico Santa María, located in Valparaíso, Chile. The procedure can be summarized in six main steps:

1. The positioning system was mounted in the clamp of robotic arm to simulate the UAV attitude.

2. The parameter reference separation by the acquisition an image set (30 images) at a fixed attitude in off-line mode was proposed.

3. The operator set up the robot height with respect to wires of the model, and the path to be followed by the robot.

4. The robotic arm automatically moved on the pre-determined path, recording a video sequence.

5. Visual data were analyzed in MATLAB programming environment (MathWorks, Natick, MA, USA). The robotic arm position provided by the software from the manufacturer was used as the reference in each experiment.

6. The estimated placement of the camera was shown in a graphical user interface (GUI).

Three experiments were carried out to prove the algorithm behavior: straight line path, circular path, and circular variable path. Figure 6 shows schematics of experiments developed in indoor tests. 


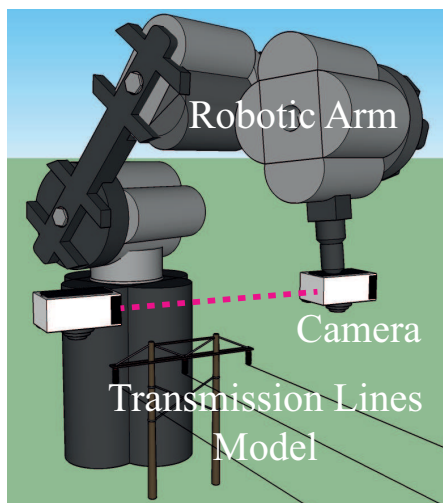

(a)

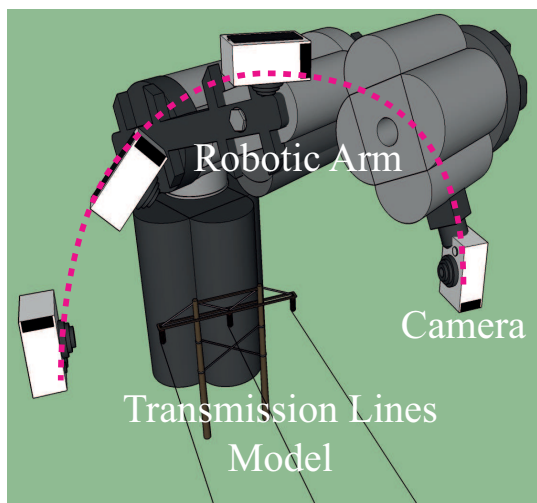

(b)

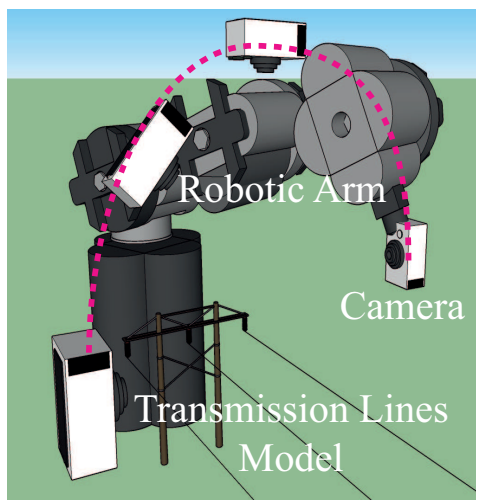

(c)

Figure 6. Paths followed by the testing robot: (a) straight line; (b) circular; and (c) circular Variable.

The first experiment consisted of moving the positioning system in a straight line path at three different heights, maintaining the camera plane fixed and parallel to the power-lines plane, as shown in Figure 7a. A database with 600 visual images was analyzed to investigate the behavior of the positioning system in each trail. It is possible to observe that the camera positioning (magenta dots) converges to the reference (blue dots) in Figure 7a for each studied height. In terms of the root medium squared error (RMSE), our approach was within this tolerance limit for this type of applications [57,58]. Furthermore, The algorithm accuracy was higher than $90.35 \%$ in the three-phase system detection, as shown in Table 2a.

Table 2. Laboratory results. Statistical analysis of different developed experiments: (a) straight line path; (b) circular path; and (c) circular variable path.

\begin{tabular}{|c|c|c|c|c|}
\hline \multicolumn{5}{|c|}{ (a) } \\
\hline Height mm & 650 & 850 & 1050 & \\
\hline Analyzed frames & 600 & 600 & 600 & \\
\hline True positives & 543 & 575 & 573 & \\
\hline Accuracy \% & 90.35 & 95.67 & 95.53 & \\
\hline RMSE mm & 18.94 & 13.81 & 10.30 & \\
\hline \multicolumn{5}{|c|}{ (b) } \\
\hline Radius mm & 550 & 650 & 850 & 950 \\
\hline Analyzed frames & 1003 & 1143 & 1247 & 1174 \\
\hline True positives & 882 & 898 & 1144 & 984 \\
\hline Accuracy \% & 87.93 & 78.5 & 91.7 & 83.7 \\
\hline RMSE mm & 47.74 & 55.77 & 63.69 & 58.44 \\
\hline \multicolumn{5}{|c|}{ (c) } \\
\hline Radius mm & 550 & 650 & 850 & 950 \\
\hline Analyzed frames & 1003 & 1143 & 1247 & 1174 \\
\hline True positives & 973 & 1061 & 1128 & 1093 \\
\hline Accuracy \% & 96.9 & 92.7 & 90.4 & 93 \\
\hline RMSE mm & 58.81 & 60.97 & 59.32 & 47.12 \\
\hline
\end{tabular}

The second experiment consisted of moving the positioning system in a circular path. The camera plane rotated around the power-lines plane, as shown in Figure $7 \mathrm{~b}$. The second set of data acquired from the visual sensor allowed analyzing the accuracy and reliability of relative positioning from five different radii by processing more than 1000 visual images in each trail. Results of absolute positioning are shown in Figure $7 \mathrm{~b}$ where the blue line is the height reference and the magenta line is the camera positioning and the statistical analysis is tabulated in Table $2 \mathrm{~b}$. Moreover, the algorithm accuracy was higher than $78.5 \%$ in the three-phase system detection. 
Finally, we developed an experiment, called circular variable path, that gathers the first two cases, as shown in Figure 7c. The camera plane rotates around the power-lines plane as it is not aligned with the power-lines direction. It is interesting to note that the camera positioning, in magenta color, converges to its reference in blue color and positioning errors were within expected and suitable ranges for this application, as shown in the statistical analysis developed in Table 2c. The algorithm accuracy was higher than $90.4 \%$ in the three-phase system detection.

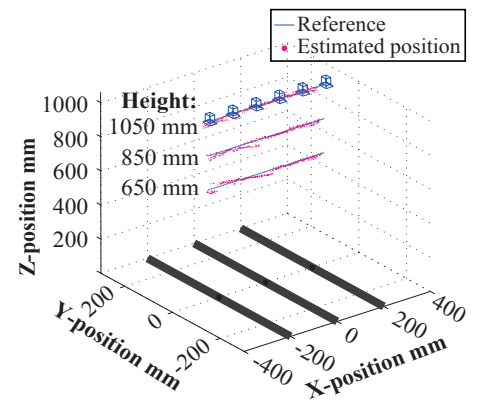

(a)

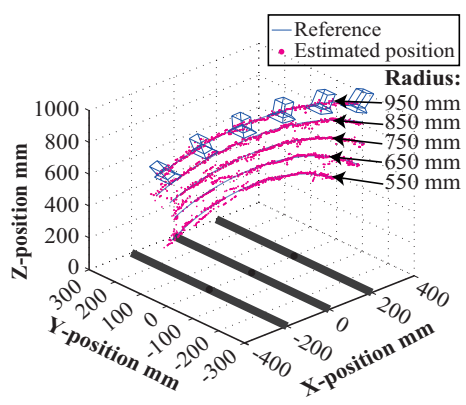

(b)

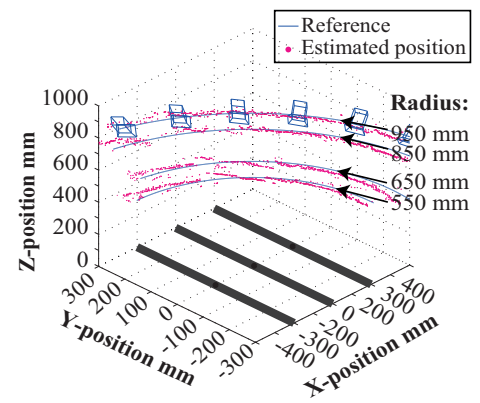

(c)

Figure 7. Laboratory results. Comparative analysis between pre-established path and estimated path by our approach (blue boxes represents the spatial position of the camera): (a) straight line path; (b) circular path; and (c) circular variable path.

\subsection{Simulation Results}

Gazebo software was used to study the behavior of a simulated UAV, equipped with our system. The working environment consisted of three-phase transmission grid, whose main characteristics are summarized in Table 3, a simulated UAV and a simulated visual camera. In addition, the pre-calibrated algorithm was programmed in $\mathrm{C} / \mathrm{C}++$ under Ubuntu 16.04 operating system to reduce the processing time. The procedure can be summarized in three main steps:

1. First, the parameter reference separation by the acquisition an image set (30 images) at a fixed attitude in off-line mode was proposed.

2. Then, the simulated UAV automatically flew on the pre-determinate path, acquiring the visual data.

3. Finally, our approach analyzed the data and returned the estimated placement of the UAV in real time. At the same time, the results were plotted in a GUI, developed in MATLAB programming environment.

Table 3. Transmission line parameters in GAZEBO environment.

\begin{tabular}{cc}
\hline Parameter & Transmission Line $500 \mathbf{~ k V}$ \\
\hline Height & $20 \mathrm{~m}$ \\
$\begin{array}{c}3 \phi \text {-Separation } \\
\text { Distribution }\end{array}$ & $10.50 \mathrm{~m}$ between phases \\
\hline
\end{tabular}

Two experiments were developed in the simulated environment. First, the UAV attitude was maintained all the time. The corresponding results are shown in Figure 8. It is possible to determine that the estimated placement converges to the simulated configuration and the absolute error of the positioning system was less than $1 \%$.

Under the same conditions, the simulated UAV was maintained at constant height and flew over the simulated transmission lines, as shown in Figure 9. It is possible to see that the estimated placement converges to the simulated configuration, provided that the transmission lines are visible in the analyzed images. Otherwise, the system was able to delete the false estimations, providing better performance. 


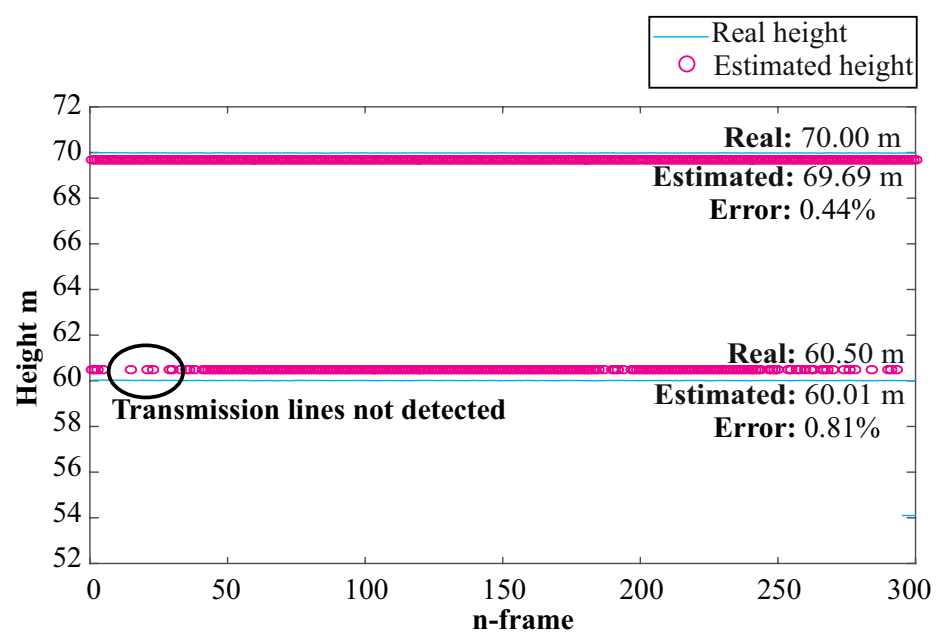

Figure 8. Results of the simulation: Stationary flight of the UAV (flight altitude: $55 \mathrm{~m}, 60 \mathrm{~m}$ and $70 \mathrm{~m}$ to conductors) with frames where transmission lines were not detected.

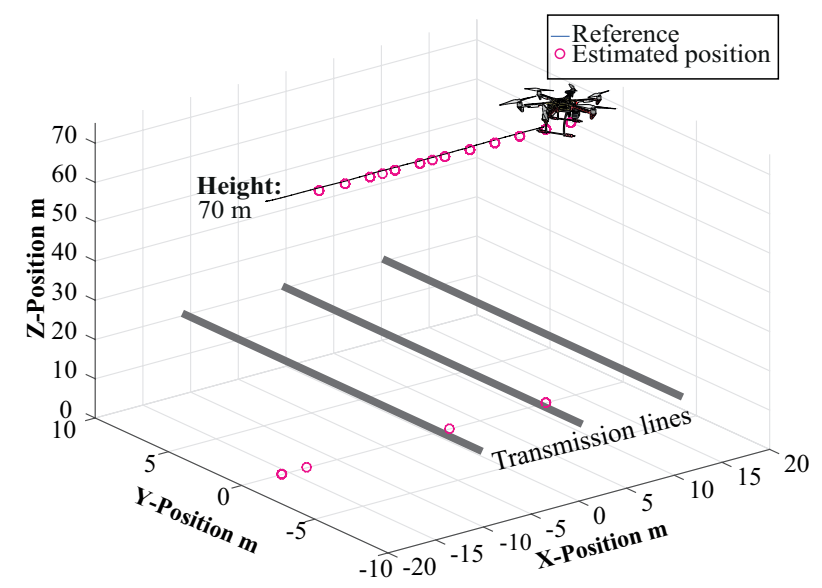

Figure 9. Results of simulation: Comparative analysis between pre-establish path and estimated path by our approach (straight line path).

\subsection{Transmission Line Detection Algorithm}

Figure 10 presents the resultant images in all stages of the transmission line detection approach, with regards to: (a) images analyzed under ideal lighting conditions; (b) image brightness increased by $20 \%$; (c) image brightness increased by $60 \%$; and (d) image brightness reduced by $50 \%$.

The acquired image has additional objects, which are not related to the transmission lines. These objects from the scene have to be filtered or eliminated to isolate the conductors. First, the color constraint is applied to obtain a gray-scale image. Then, the image brightness is corrected to highlight power conductors. Finally, the delivered image is filtered using Gabor filters, which simultaneously remove the background noise of power lines as well as generate edge maps. It is possible to observe that the system highlights power conductors. However, the delivered image was noisy due to complex and irregular ground coverage. It is possible to observe that the system highlights power conductors. However, the delivered image was noisy due to complex and irregular ground coverage. This disadvantage increases the risk of the positioning system returns erroneous measurements.

The direct bright sunshine can affect the positioning system since the system could not detect wires and conductors, as shown in Figure 10b,c. Therefore, the system was not able to find and isolate power-lines in the image. On the other hand, the system could operate under reduced visibility conditions but not in darkness, as shown in Figure 10d. 

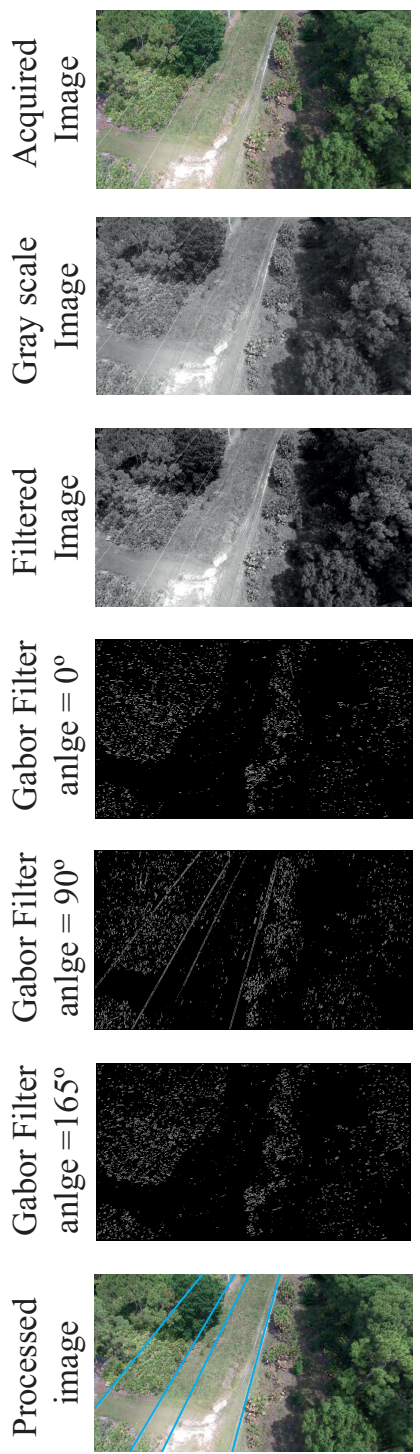

(a)
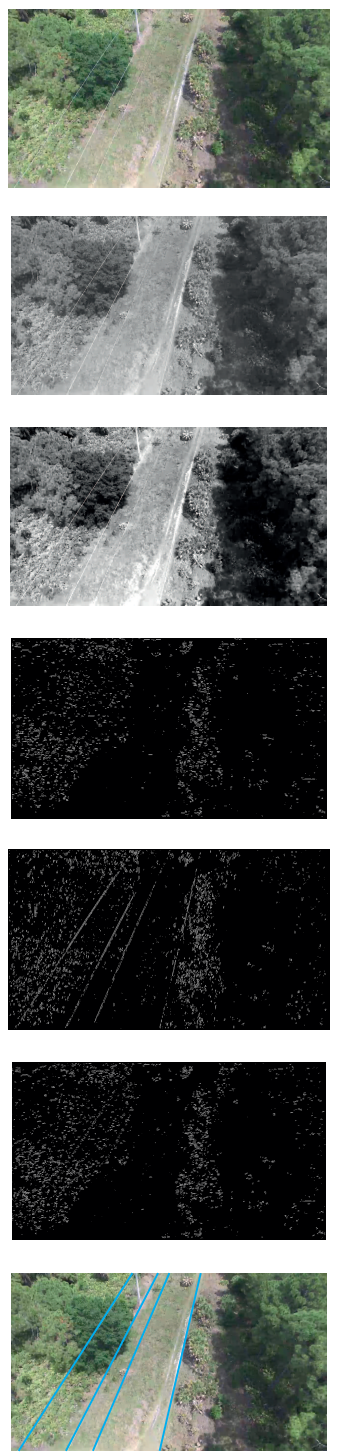

(b)
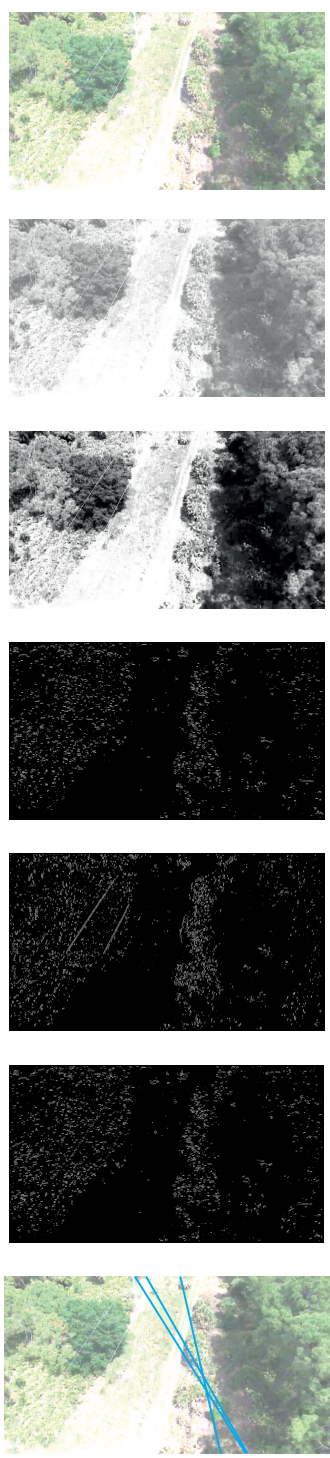

(c)
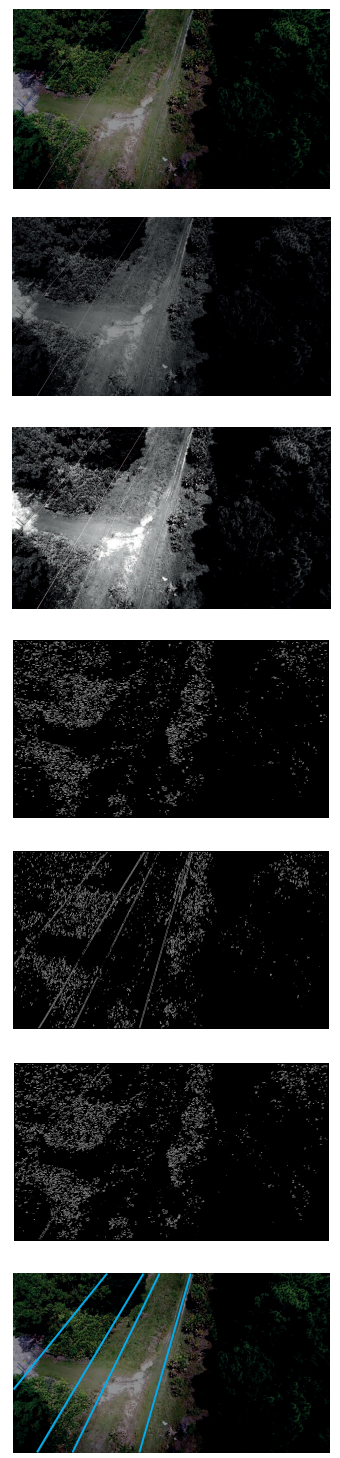

(d)

Figure 10. Comparison of power line detection results: (a) ideal lighting conditions; (b) brightness increased by $20 \%$; (c) brightness increased by $60 \%$; and (d) brightness reduced by $50 \%$.

\subsection{Field Experiment Results}

The positioning system was mounted on a commercial UAV, and equipped by the UTFSM Robotics Research Group (GRAI). The complete system was positioned over a transmission system, whose main parameters are summarized in Table 4. The estimate based on the embedded Kalman Filter was used as position reference of the UAV. Figure 11 presents the resultant images in all stages of the transmission line detection approach. The corresponding results are shown in Figures 12 and 13. It is interesting to note that the estimated position, shown as a magenta dashed line, converges to reference (black line), provided that the transmission lines are visible in the acquired images, as shown in Figures 12 and 13. Otherwise, the system compensates poor estimations using Bayesian methods. In this context, we used the estimator described in Equations (7) and (8) to reduce this negative effect. Table 5 compares the results obtained in the position estimation, after applying two approaches: simple when the system returns the position and hybrid when the sensor fusion expression only with the IMU, GNSS and our approach data. The impact of this solution is shown in Figures 12 and 13, as a cyan dashed line, where it is possible to note that the system determined the UAV position in the hybrid case despite not seeing wires, giving the robustness to the system. In terms of the RMSE, the two approaches show similar 
results, although the hybrid method proposed here was slightly smaller and the positioning errors were, respectively, less than $66.02 \mathrm{~cm}$ (x estimation) and $26.29 \mathrm{~cm}$ (z estimation) in the simple case and $25.77 \mathrm{~cm}$ (x estimation) and $10.26 \mathrm{~cm}$ (z estimation) in the hybrid case. Results shows a proper behavior for aerial applications. On the other hand, the algorithm accuracy was $91.44 \%$ in three-phase system detection. These results show that the system serves to locate any robotic platform in a transmission grid, under variable lighting conditions or GNSS restrictions.

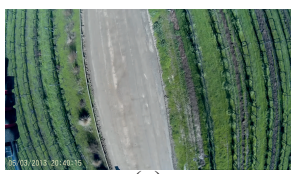

(a)

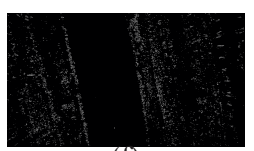

(f)

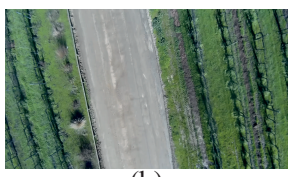

(b)

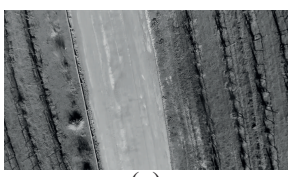

(c)

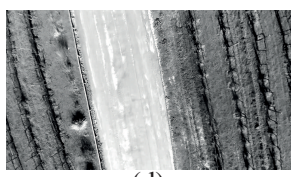

(d)

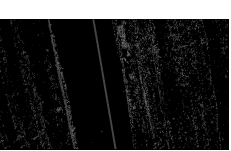

(j)

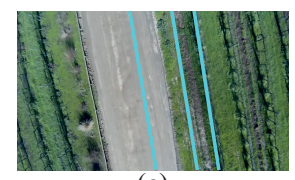

(e)

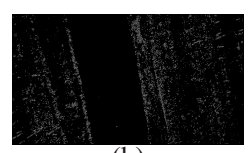

(k)

Figure 11. Results of power line detection algorithm: (a) acquired image; (b) orthorectified image; (c) gray scale image; (d) filtered image; (e) power lines detected; and (i-k) images filtered by Gabor filters.

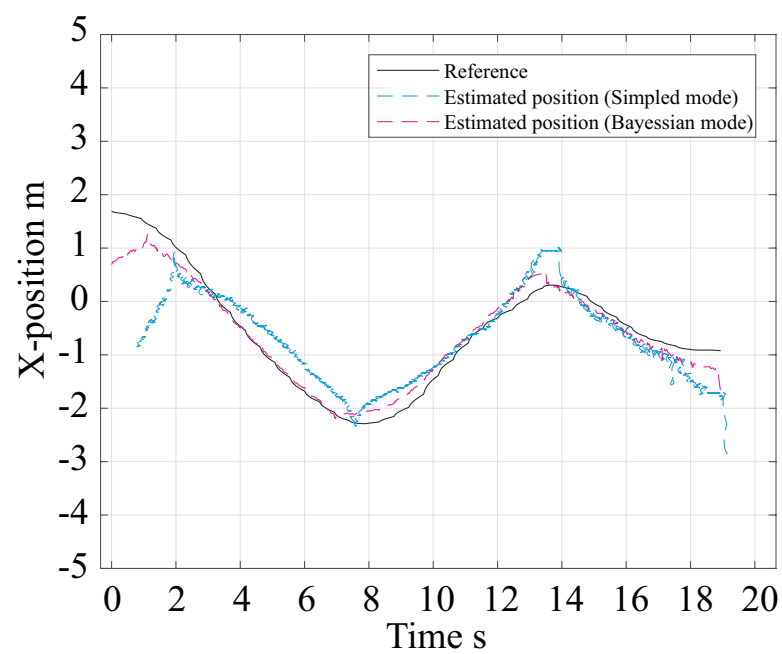

Figure 12. Positioning of our UAV over transmission grid: X-position

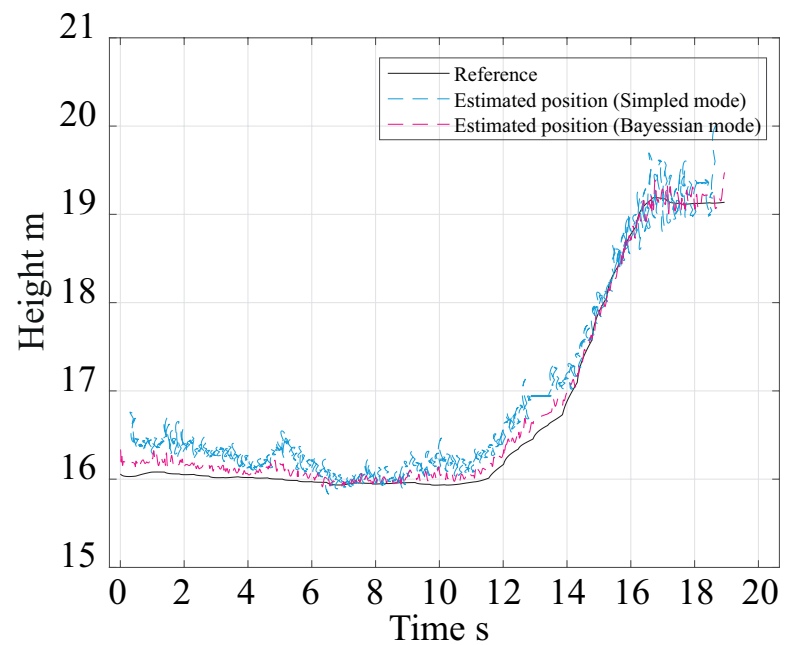

Figure 13. Positioning of our UAV over transmission grid: Z-position (height). 
Table 4. Structural characteristics of the transmission grid.

\begin{tabular}{cc}
\hline Parameter & Transmission Line $68 \mathbf{~ k V}$ \\
\hline Height & $12 \mathrm{~m}$ \\
& $2.4 \mathrm{~m}$ between left and right wire \\
$3 \phi$-Separation & $1.6 \mathrm{~m}$ between left and center wire \\
& $0.8 \mathrm{~m}$ between right and center wire \\
Distribution & Horizontal \\
\hline
\end{tabular}

Table 5. Field results: Statistical analysis of different developed experiments.

\begin{tabular}{cccccc}
\hline Frames & $\begin{array}{c}\text { True } \\
\text { Positi-ves }\end{array}$ & $\begin{array}{c}\text { False } \\
\text { Positi-ves }\end{array}$ & Effici-ency & $\begin{array}{c}\text { RMSE X } \\
\text { Estimator } \mathbf{~}\end{array}$ & $\begin{array}{c}\text { RMSE Z } \\
\text { Estimator } \mathbf{~}\end{array}$ \\
\hline 549 & 502 & 47 & $91.44 \%$ & 0.2577 & 0.1026 \\
\hline
\end{tabular}

\section{Discussion}

In this study, a positioning system based on computer vision was proposed. The experimental results show that the system is capable of detecting transmission lines with approximately $91.44 \%$ accuracy for each studied case. The system analyzed the geometric patterns of transmission lines. For this reason, the previous training is not necessary. The main disadvantage was related to data acquisition and the camera resolution, since it affects the detection of the wires.

Once that three-phase system (three conductors) was segmented, the system was capable of computing the UAV position respect to three-phase system. We presented two approaches: simple and hybrid methods. Based on RMSE, the positioning errors were less than $66.02 \mathrm{~cm}$ (x estimation) and $26.29 \mathrm{~cm}$ (z estimation) for the simple method, and $25.77 \mathrm{~cm}$ and $10.26 \mathrm{~cm}$ for the hybrid method. These results are adequate for aerial applications.

\subsection{Consistency Test}

To evaluate the visual based transmission line positioning system, we performed consistency tests following the guidelines presented in [59]. Figure 14 shows the consistency of the estimation of the $x$ and $z$ coordinates of the drone flying over the transmission lines, in Figure 14a,b, respectively. As can be seen, the error in both coordinates remains bounded by two times its standard deviation. As ground truth (and only with the aim of performing the consistency tests) we used the GNSS positioning system described in Section 2.

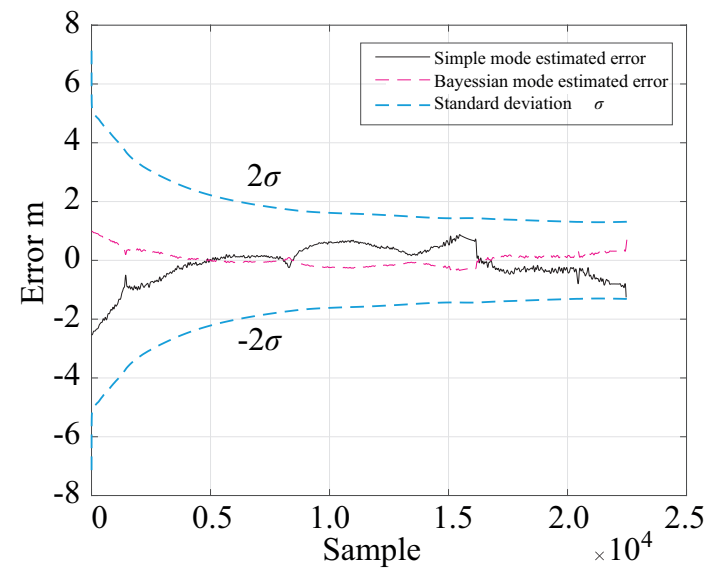

(a)

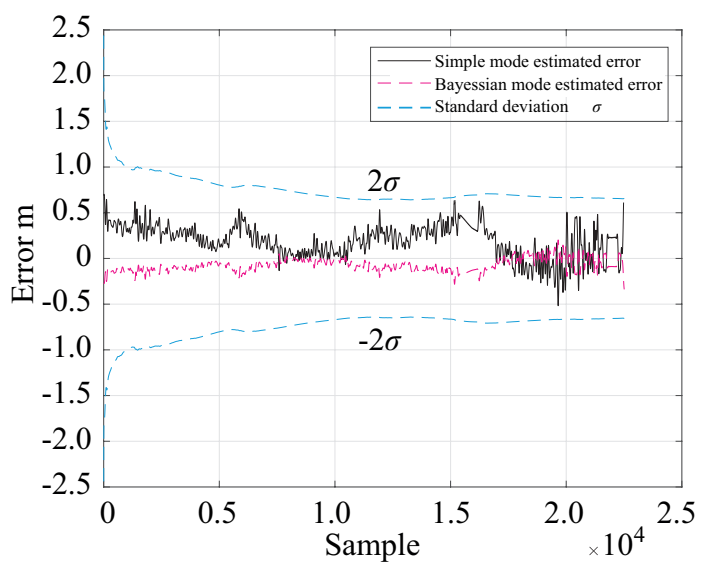

(b)

Figure 14. Consistent tests: (a) the consistency of the error in the $x$ coordinate; and (b) the consistency of the error in the $z$ coordinate. 


\subsection{Comparison with Existing Positioning Techniques}

Existing positioning architectures are broadly classified as proprioceptive and exteroceptive by this manuscript. By regarding this separation and the frequency of preference, some leading positioning methods are discussed, and a detailed comparison is shown in Figure 15 and the main characteristics are summarized in Table 6.

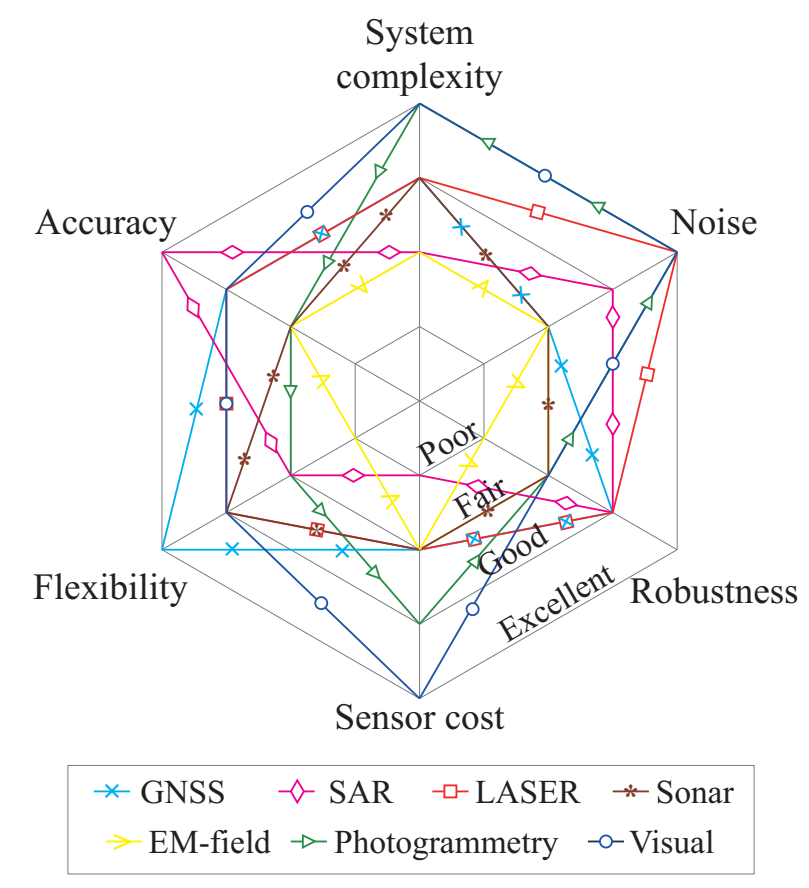

Figure 15. Comparison of the existing positioning techniques.

\subsubsection{GNSS-IMU}

GNSS and IMU are the most important parts of the UAV navigation systems. Currently, GNSS-IMU navigation is the most adopted sensing mode to locate aerial platform in transmission grids. However, this method is restricted by size and weight constraints and sensors can be affected by electromagnetic interference. 
Table 6. Comparison of the existing positioning methods

\begin{tabular}{|c|c|c|c|c|}
\hline & Characteristics & Advantages & Disadvantages & Works \\
\hline GNSS-IMU & $\begin{array}{l}\text {-Proprioceptive, Ambient } \\
\text {-GNSS and IMU are the base of a } \\
\text { navigation system }\end{array}$ & $\begin{array}{l}\text {-Independent of the grid } \\
\text {-High accuracy } \\
\text {-Not dependent on external lighting conditions }\end{array}$ & $\begin{array}{l}\text {-Size and weight constraints } \\
\text {-High-resolution data is very costly } \\
\text {-Not always available (GNSS-denied areas) } \\
\text {-At least } 3 \text { satellites should be detected } \\
\text {-The system can be affected by EMIs }\end{array}$ & {$[60,61]$} \\
\hline SAR images & $\begin{array}{l}\text {-Exteroceptive, Non-ambient } \\
\text {-Mapping of power lines and towers } \\
\text { Disaster monitoring, damaged towers }\end{array}$ & $\begin{array}{l}\text {-Covers vast areas with few images } \\
\text {-Noise immunity, high accuracy } \\
\text {-All-weather imaging capability } \\
\text {-Independent of the grid }\end{array}$ & $\begin{array}{l}\text {-Very high-resolution data is very costly } \\
\text {-Not easy to interpret } \\
\text {-Depending on environmental conditions }\end{array}$ & {$[62-64]$} \\
\hline LASER & $\begin{array}{l}\text {-Exteroceptive, Non-ambient } \\
\text {-Mapping of power conductors and towers } \\
\text {-Vegetation monitoring }\end{array}$ & $\begin{array}{l}\text {-Detailed 3D data directly available } \\
\text {-Noise immunity, high accuracy } \\
\text {-Not dependent on external lighting conditions } \\
\text {-Flexibility in data acquisition }\end{array}$ & $\begin{array}{l}\text {-Small objects are difficult to detect } \\
\text {-High-resolution data is very costly } \\
\text {-Depending on the scanning geometry }\end{array}$ & {$[38,62,65,66]$} \\
\hline Sonar & $\begin{array}{l}\text {-Exteroceptive, Non-ambient } \\
\text {-Mapping of conductors and pylons } \\
\text {-Inspection of power line components } \\
\text {-Detect partial discharges in power lines }\end{array}$ & $\begin{array}{l}\text {-Easy to implements } \\
\text {-Non-complex structure } \\
\text {-Independent of the grid } \\
\text {-Low costs compared to other methods }\end{array}$ & $\begin{array}{l}\text {-Highly affected by noise } \\
\text {-Low resolution }\end{array}$ & {$[67,68]$} \\
\hline EM-field & $\begin{array}{l}\text {-Exteroceptive, Non-ambient } \\
\text {-Inspection of power line components } \\
\text {-Measures the voltage drop across wires }\end{array}$ & $\begin{array}{l}\text {-Easy to implements } \\
\text {-Non-complex structure } \\
\text {-Not available when power lines are off }\end{array}$ & $\begin{array}{l}\text {-Requires high and perpetual current flow } \\
\text {-Safety vulnerabilities } \\
\text {-Mechanical constrains }\end{array}$ & {$[69,70]$} \\
\hline Photogrammetry & $\begin{array}{l}\text {-Exteroceptive, Non-ambient } \\
\text {-Vegetation monitoring } \\
\text {-Mapping of conductors and towers } \\
\text {-Fault monitoring in power line components }\end{array}$ & $\begin{array}{l}\text {-Very detailed 3D data directly by laser scanning } \\
\text {-High flexibility in data acquisition } \\
\text {-Low costs compared to other methods } \\
\text {-Potential for diverse applications } \\
\text {-Noise immunity }\end{array}$ & $\begin{array}{l}\text {-Off-line mode, High computational cost } \\
\text {-The method needs landmarks to correct } \\
\text { the scale } \\
\text {-Camera parameters affect directly to measurements } \\
\text {-The technique needs high resolution } \\
\text {-It depends on lighting conditions }\end{array}$ & {$[41,49]$} \\
\hline Visual & $\begin{array}{l}\text {-Exteroceptive, Non-ambient } \\
\text {-Vegetation monitoring } \\
\text {-Inspection of power line equipment } \\
\text {-Mapping of conductors and ground wires }\end{array}$ & $\begin{array}{l}\text {-High spatial resolution } \\
\text {-High flexibility in data acquisition } \\
\text {-Possibility of height measurements from } \\
\text { visual odometry } \\
\text {-Low costs compared to other methods } \\
\text {-Noise immunity }\end{array}$ & $\begin{array}{l}\text {-Cannot be obtained through clouds or in } \\
\text { dark conditions } \\
\text {-The image quality can be affected by vibrations. } \\
\text {-Camera parameters directly affect the measurements } \\
\text {-It depends on lighting and weather conditions } \\
\text {-Dependent of the grid }\end{array}$ & {$[62,71]$} \\
\hline
\end{tabular}




\subsubsection{Synthetic Aperture Radars}

For the positioning of transmission line aerial platforms, synthetic aperture radars (SAR) can be used for mapping of power lines and towers, monitoring environmental disasters and vegetation mapping. Although these systems offer sufficient solutions in terms of continuous functioning under variable environmental conditions and environmental three-dimensional modeling (vegetation, power structure, and elevation), SAR images are not easy to interpret and they are very expensive depending on the resolution. In addition, The visibility of power conductors can be extremely poor, depending on factors such as viewing geometry.

\subsubsection{Light-Pulse Distance Sensing}

This direct method uses a laser diode (sender and receiver) to detect transmission lines. The main applications are the mapping of conductors and pylons and detection of trees near the transmission grid. Its advantage lies in its accuracy, noise immunity and its robustness under variable lighting conditions. However, several point clouds have to be acquired for mapping small and narrow objects and the sensor technology can be highly expensive.

\subsubsection{Sonar-Pulse Distance Sensing}

Ultrasonic waves are sent from the sensor and then collected back to estimate the distance of an object from UAV. This method has several restrictions related to environmental noise, UAV flight altitude, and a low resolution. In addition, this method is irregular if too much noise is present in the environment.

\subsubsection{Electric and Magnetic-Field Change Sensing}

These sensors can be used to sense the presence of magnetic objects and fields and can be helpful in determining the position of the drone. However, the calculation of the electric and magnetic field is extremely complicated, and several electromagnetic interference sources and the noise can affect the measurements.

\subsubsection{Photogrammetry and Visual-Based Positioning}

The positioning based on monocular images aims the mapping of conductors in a transmission grid. In addition, optical aerial images can be used to monitor the vegetation, to inspect power line components and to map electrical towers. This method stands as a promising candidate to position aerial platforms in transmission grids due to its flexibility in data acquisition, low cost, and noise immunity. However, several factors can affect image quality. In addition, the lighting conditions are an important restriction (cannot be used in dark conditions). The 3D modeling of conductors is extremely difficult and depends on weather conditions.

\section{Conclusions}

Aerial remote sensing based on UAVs is a new field for inspection of equipment in electrical industry, as a result of the ergonomics and flexibility of the new platforms and their high capacity access in inhospitable areas. This work put forward some artificial vision techniques applied to the exploitation of information provided for the different sensors. In this study, the performance of a low cost positioning system for aerial platforms was analyzed. Results show that the location achieves a very high precision with respect to transmission lines, with 1.5 and $27 \mathrm{~cm}$ as the worst cases in laboratory and field tests, respectively. In addition, the system can operate under different lighting conditions and on GNSS-denied areas. The system was tested over distribution grid located in agricultural environments. There are still other tests to be performed to have a complete guarantee. Experiments showed very good performance in the platform positioning, behaving similarly in all experiments and within expected and suitable ranges for this application. Although the system has 
been specially designed for UAVs, its operating system is flexible to add on to other platforms, since it does not depend on the platform type. Moreover, the computational cost was suitable for controlling a UAV. The absence of such commercially available technology will lead the authors future work to design, develop and test more efficient hardware and accurate processing algorithms.

Author Contributions: Conceptualization, O.M., M.P. and F.A.C.; Methodology, O.M.; Software, O.M.; Validation, O.M., R.G. and F.A.C.; Formal Analysis, O.M.; Investigation, O.M., R.G, M.P. and F.A.C.; Resources, M.P. and F.A.C.; Data Curation, O.M.; Writing-Original Draft Preparation, O.M. and F.A.C.; Writing-Review and Editing, F.A.C.; Visualization, O.M.; Supervision, M.P. and F.A.C.; Project Administration, F.A.C.; and Funding Acquisition, F.A.C. and O.M.

Funding: This work was supported in part by the Advanced Center of Electrical and Electronic Engineering AC3E (CONICYT/FB0008), CONICYT-PFCHA/Doctorado Nacional/2015-21151338 and DGIIP-UTFSM Chile.

Acknowledgments: We would like to thank the Universidad Técnica Federico Santa María and the Advanced Center of Electrical and Electronic Engineering AC3E.

Conflicts of Interest: The authors declare no conflict of interest.

\section{References}

1. Bompard, E.; Huang, T.; Wu, Y.; Cremenescu, M. Classification and trend analysis of threats origins to the security of power systems. Int. J. Electr. Power Energy Syst. 2013, 50, 50-64. [CrossRef]

2. Qin, X.; Wu, G.; Ye, X.; Huang, L.; Lei, J. A Novel Method to Reconstruct Overhead High-Voltage Power Lines Using Cable Inspection Robot LiDAR Data. Remote Sens. 2017, 9, 753. [CrossRef]

3. Pentland, W. Blackout Risk Tool Puts Price Tag on Power Reliability, $2013 . \quad$ Available online: https:/ / www.forbes.com/sites/williampentland/2013/08/30/blackout-risk-tool-puts-price-tagon-power-reliability/\#73921998acf2 (accessed on 23 October 2017).

4. Henneaux, P.; Labeau, P.E.; Maun, J.C. Blackout Probabilistic Risk Assessment and Thermal Effects: Impacts of Changes in Generation. IEEE Trans. Power Syst. 2013, 28, 4722-4731. [CrossRef]

5. Lv, Z.; Song, H.; Basanta-Val, P.; Steed, A.; Jo, M. Next-Generation Big Data Analytics: State of the Art, Challenges, and Future Research Topics. IEEE Trans. Ind. Inform. 2017, 13, 1891-1899. [CrossRef]

6. Wan, J.; Tang, S.; Li, D.; Wang, S.; Liu, C.; Abbas, H.; Vasilakos, A.V. A Manufacturing Big Data Solution for Active Preventive Maintenance. IEEE Trans. Ind. Inform. 2017, 13, 2039-2047. [CrossRef]

7. Filonenko, A.; Hernández, D.C.; Jo, K.H. Fast Smoke Detection for Video Surveillance using CUDA. IEEE Trans. Ind. Inform. 2018, 14, 725-733. [CrossRef]

8. Pournaras, E.; Espejo-Uribe, J. Self-Repairable Smart Grids Via Online Coordination of Smart Transformers. IEEE Trans. Ind. Inform. 2017, 13, 1783-1793. [CrossRef]

9. Menendez, O.; Cheein, F.A.A.; Perez, M.; Kouro, S. Robotics in Power Systems: Enabling a More Reliable and Safe Grid. IEEE Ind. Electron. Mag. 2017, 11, 22-34. [CrossRef]

10. Wang, Y.; Liu, H.; Long, H.; Zhang, Z.; Yang, S. Differential Evolution with A New Encoding Mechanism for Optimizing Wind Farm Layout. IEEE Trans. Ind. Inform. 2018, 14, 1040-1054. [CrossRef]

11. Li, Z.; Bruggemann, T.S.; Ford, J.J.; Mejias, L.; Liu, Y. Toward automated power line corridor monitoring using advanced aircraft control and multisource feature fusion. J. Field Robot. 2012, 29, 4-24. [CrossRef]

12. Phillips, A. Future Inspection of Overhead Transmission Lines; Electric Power Research Institute: Palo Alto, CA, USA, 2008.

13. Elizondo, D.; Gentile, T.; Candia, H.; Bell, G. Overview of robotic applications for energized transmission line work-Technologies, field projects and future developments. In Proceedings of the 2010 1st International Conference on Applied Robotics for the Power Industry, Montréal, QC, Canada, 5-7 October 2010; pp. 1-7. [CrossRef]

14. Song, Y.; Wang, H.; Jiang, Y.; Ling, L. AApe-D: A novel power transmission line maintenance robot for broken strand repair. In Proceedings of the 2012 2nd International Conference on Applied Robotics for the Power Industry (CARPI), Zurich, Switzerland, 11-13 September 2012; pp. 108-113. [CrossRef]

15. Chan, J. Tools for Conductor Evaluation: State of the Art Review and Promising Technologie; Electric Power Research Institute: Palo Alto, CA, USA, 2003. 
16. Cho, B.H.; Byun, S.H.; Park, J.Y.; Kim, J.S. Development of Automatic Inspection Robot for Live-line Insulators. In Proceedings of the IEEE 11th 2006 International Conference on Transmission Distribution Construction, Operation and Live-Line Maintenance, ESMO 2006, Albuquerque, NM, USA, 15-19 October 2006. [CrossRef]

17. Xia, Y.; Jiang, X.; Zhang, Z.; Hu, J.; Sun, C. Detecting broken strands in transmission line-Part 1: Design of a smart eddy current transducer carried by inspection robot. Int. Trans. Electr. Energy Syst. 2012, 23, 1409-1422. [CrossRef]

18. Fonseca Barbosa, C. An eddy current sensor for conductor inspection on energized power lines. In Proceedings of the 2014 3rd International Conference on Applied Robotics for the Power Industry (CARPI), Foz do Iguassu, Brazil, 14-16 October 2014; pp. 1-5. [CrossRef]

19. Zhu, Y.; Yan, J.; Tang, Y.; Sun, Y.L.; He, H. Joint Substation-Transmission Line Vulnerability Assessment Against the Smart Grid. IEEE Trans. Inf. Forensics Secur. 2015, 10, 1010-1024. [CrossRef]

20. Douglass, D.; Chisholm, W.; Davidson, G.; Grant, I.; Lindsey, K.; Lancaster, M.; Lawry, D.; McCarthy, T.; Nascimento, C.; Pasha, M.; et al. Real-Time Overhead Transmission-Line Monitoring for Dynamic Rating. IEEE Trans. Power Deliv. 2016, 31, 921-927. [CrossRef]

21. Wang, J.J.; Chan, J.K.; Graziano, J.A. The Lifetime Estimate for ACSR Single-Stage Splice Connector Operating at Higher Temperatures. IEEE Trans. Power Deliv. 2011, 26, 1317-1325. [CrossRef]

22. Bortoni, E.C.; Santos, L.; Bastos, G.S. A Model to Extract Wind Influence from Outdoor IR Thermal Inspections. IEEE Trans. Power Deliv. 2013, 28, 1969-1970. [CrossRef]

23. De Paulis, F.; Olivieri, C.; Orlandi, A.; Giannuzzi, G.; Bassi, F.; Morandini, C.; Fiorucci, E.; Bucci, G. Exploring Remote Monitoring of Degraded Compression and Bolted Joints in HV Power Transmission Lines. IEEE Trans. Power Deliv. 2016, 31, 2179-2187. [CrossRef]

24. Oliveira, S.C.; Fontana, E. Optical Detection of Partial Discharges on Insulator Strings of High-Voltage Transmission Lines. IEEE Trans. Instrum. Meas. 2009, 58, 2328-2334. [CrossRef]

25. Li, L.; Gu, Y.; Hao, Y.; Xue, Y.; Xiong, G.; Yang, L.; Zhang, F. Shed parameters optimization of composite post insulators for UHV DC flashover voltages at high altitudes. IEEE Trans. Dielectr. Electr. Insul. 2015, 22, 169-176. [CrossRef]

26. Ma, G.M.; Li, Y.B.; Mao, N.Q.; Shi, C.; Li, C.r.; Zhang, B. A Fiber Bragg Grating-Based Dynamic Tension Detection System for Overhead Transmission Line Galloping. Sensors 2018, 18, 365. [CrossRef]

27. Sorqvist, T.; Gubanski, S.M. Leakage current and flashover of field-aged polymeric insulators. IEEE Trans. Dielectr. Electr. Insul. 1999, 6, 744-753. [CrossRef]

28. Devine, C.W.; O'Connell, D.N. Boom Mountable Robotic Arm. U.S. Patent 8,684,333, 13 March 2014.

29. Roncolatto, R.; Romanelli, N.; Hirakawa, A.; Horikawa, O.; Vieira, D.; Yamamoto, R.; Finotto, V. Robotics applied for safety improvement in the power distribution lines maintenance. In Proceedings of the Transmission and Distribution Conference and Exposition, Chicago, IL, USA, 21-24 April 2008; pp. 1-7. [CrossRef]

30. Aracil, R.; Ferre, M.; Hernando, M.; Pinto, E.; Sebastian, J. Telerobotic system for live-power line maintenance: ROBTET. Control Eng. Pract. 2002, 10, 1271-1281. [CrossRef]

31. Innovation, M. Linerover-A Compact Robot for Inspecting Overhead Lines. Available online: http: / / www.hydroquebec.com/robotics/distribution-solutions-linerover.html (accessed on 29 November 2016).

32. CORP, H. Expliner-Robot for Power Line Inspection. Available online: https://www.hibot.co.jp (accessed on 29 November 2016).

33. Innovation, M. Linescout-A Versatile Robot for Inspecting Overhead Lines. Available online: http: / / www.hydroquebec.com/robotics/transmission-solutions-linescout.html (accessed on 29 November 2016).

34. GEOSYSTEMS, H. AIBOTIX. Available online: https://www.aibotix.com/ (accessed on 15 December 2016).

35. Chen, C.; Yang, B.; Song, S.; Peng, X.; Huang, R. Automatic Clearance Anomaly Detection for Transmission Line Corridors Utilizing UAV-Borne LIDAR Data. Remote Sens. 2018, 10, 613. [CrossRef]

36. Nemra, A.; Aouf, N. Robust INS/GPS Sensor Fusion for UAV Localization Using SDRE Nonlinear Filtering. IEEE Sens. J. 2010, 10, 789-798. [CrossRef]

37. Mebarki, R.; Lippiello, V.; Siciliano, B. Nonlinear Visual Control of Unmanned Aerial Vehicles in GPS-Denied Environments. IEEE Trans. Robot. 2015, 31, 1004-1017. [CrossRef]

38. Wang, Y.; Chen, Q.; Liu, L.; Zheng, D.; Li, C.; Li, K. Supervised Classification of Power Lines from Airborne LiDAR Data in Urban Areas. Remote Sens. 2017, 9, 771. [CrossRef] 
39. Berni, J.A.J.; Zarco-Tejada, P.J.; Suarez, L.; Fereres, E. Thermal and Narrowband Multispectral Remote Sensing for Vegetation Monitoring from an Unmanned Aerial Vehicle. IEEE Trans. Geosci. Remote Sens. 2009, 47, 722-738. [CrossRef]

40. Jones, D. Aerial inspection of overhead power lines using video: Estimation of image blurring due to vehicle and camera motion. Vision Image Signal Process. IEE Proc. 2000, 147, 157-166. [CrossRef]

41. Jiang, S.; Jiang, W.; Huang, W.; Yang, L. UAV-Based Oblique Photogrammetry for Outdoor Data Acquisition and Offsite Visual Inspection of Transmission Line. Remote Sens. 2017, 9, 278. [CrossRef]

42. Ishino, R.; Tsutsumi, F. Detection system of damaged cables using video obtained from an aerial inspection of transmission lines. In Proceedings of the Power Engineering Society General Meeting, Denver, CO, USA, 6-10 June 2004; Volume 2, pp. 1857-1862. [CrossRef]

43. Kobayashi, Y.; Karady, G.G.; Heydt, G.T.; Olsen, R.G. The Utilization of Satellite Images to Identify Trees Endangering Transmission Lines. IEEE Trans. Power Deliv. 2009, 24, 1703-1709. [CrossRef]

44. Yan, G.; Li, C.; Zhou, G.; Zhang, W.; Li, X. Automatic Extraction of Power Lines from Aerial Images. IEEE Geosci. Remote Sens. Lett. 2007, 4, 387-391. [CrossRef]

45. Zhu, L.; Hyyppä, J. Fully-Automated Power Line Extraction from Airborne Laser Scanning Point Clouds in Forest Areas. Remote Sens. 2014, 6, 11267-11282. [CrossRef]

46. Sharma, H.; Bhujade, R.; Adithya, V.; Balamuralidhar, P. Vision-based detection of power distribution lines in complex remote surroundings. In Proceedings of the 2014 Twentieth National Conference on Communications (NCC), Kanpur, India, 28 February-2 March 2014; pp. 1-6. [CrossRef]

47. Tian, F.; Wang, Y.; Zhu, L. Power line recognition and tracking method for UAVs inspection. In Proceedings of the 2015 IEEE International Conference on Information and Automation, Lijiang, China, 8-10 August 2015; pp. 2136-2141. [CrossRef]

48. Omari, S.; Gohl, P.; Burri, M.; Achtelik, M.; Siegwart, R. Visual industrial inspection using aerial robots. In Proceedings of the 2014 3rd International Conference on Applied Robotics for the Power Industry (CARPI), Foz do Iguassu, Brazil, 14-16 October 2014; pp. 1-5. [CrossRef]

49. Guo, B.; Li, Q.; Huang, X.; Wang, C. An Improved Method for Power-Line Reconstruction from Point Cloud Data. Remote Sens. 2016, 8, 36. [CrossRef]

50. Foundation, O.S.R. ROS Indigo Igloo. Available online: http://wiki.ros.org/indigo (accessed on 27 November 2018).

51. Chen, S.; Li, Y.F. Finding Optimal Focusing Distance and Edge Blur Distribution for Weakly Calibrated 3-D Vision. IEEE Trans. Ind. Inform. 2013, 9, 1680-1687. [CrossRef]

52. Geusebroek, J.M.; Smeulders, A.W.M.; van de Weijer, J. Fast anisotropic Gauss filtering. IEEE Trans. Image Process. 2003, 12, 938-943. [CrossRef]

53. Ritteri, G.X.; Wilson, J.N. Handbook of Computer Vision Algorithms in Image Algebra; CRC Pressl: Boca Raton, FL, USA, 2001.

54. Kelly, A. Mobile Robotics Mathematics, Models and Methods; Cambridge University Press: Cambridge, UK, 2013.

55. Open Source Robotics Foundation. GAZEBO Robot Simulation Made Easy. 2014. Availanle online: http:/ / gazebosim.org/ (accessed on 22 August 2017).

56. MATLAB. Version 9.4.0.813650 (R2018a); The MathWorks Inc.: Natick, MA, USA, 2018.

57. Kim, J.; Sukkarieh, S. Autonomous airborne navigation in unknown terrain environments. IEEE Trans. Aerosp. Electron. Syst. 2004, 40, 1031-1045. [CrossRef]

58. Tang, Y.; Hu, Y.; Cui, J.; Liao, F.; Lao, M.; Lin, F.; Teo, R.S.H. Vision-Aided Multi-UAV Autonomous Flocking in GPS-Denied Environment. IEEE Trans. Ind. Electron. 2019, 66, 616-626. [CrossRef]

59. Mao, G.; Fidan, B. Localization Algorithms and Strategies for Wireless Sensor Networks, 1st ed.; Information Science Reference-Imprint of IGI Publishing: Hershey, PA, USA, 2009.

60. Moore, A.J.; Schubert, M.; Rymer, N. Autonomous Inspection of Electrical Transmission Structures with Airborne UV Sensors: NASA Report On Dominion Virginia Power Flights of November 2016; National Aeronautics and Space Administration, Langley Research Center: Hampton, VA, USA, 2017.

61. El-Sheimy, N. An Overview of Mobile Mapping Systems. 2005. Available online: https:/ /www.researchgate .net/publication/237455692_An_Overview_of_Mobile_Mapping_Systems (accessed on 18 December 2018).

62. Matikainen, L.; Lehtomäki, M.; Ahokas, E.; Hyyppä, J.; Karjalainen, M.; Jaakkola, A.; Kukko, A.; Heinonen, T. Remote sensing methods for power line corridor surveys. ISPRS J. Photogramm. Remote Sens. 2016, 119, $10-31$. [CrossRef] 
63. Xie, L.; Zhang, H.; Wang, C.; Zhang, B.; Wu, F. High-voltage transmission towers detection using hybrid polarimetric SAR data. In Proceedings of the 2014 Third International Workshop on Earth Observation and Remote Sensing Applications (EORSA), Changsha, China, 11-14 June 2014; pp. 353-356. [CrossRef]

64. Lin, Y.; Hong, W.; Tan, W.; Wang, Y.; Xiang, M. Airborne circular SAR imaging: Results at P-band. In Proceedings of the 2012 IEEE International Geoscience and Remote Sensing Symposium, Munich, Germany, 22-27 July 2012; pp. 5594-5597. [CrossRef]

65. Deng, C.; Liu, J.; Liu, Y.; Tan, Y. Real time autonomous transmission line following system for quadrotor helicopters. In Proceedings of the 2016 International Conference on Smart Grid and Clean Energy Technologies (ICSGCE), Chengdu, China, 19-22 October 2016; pp. 61-64. [CrossRef]

66. McLaughlin, R.A. Extracting transmission lines from airborne LIDAR data. IEEE Geosci. Remote Sens. Lett. 2006, 3, 222-226. [CrossRef]

67. Wu, K.J.; Gregory, T.S.; Moore, J.; Hooper, B.; Lewis, D.; Tse, Z.T.H. Development of an indoor guidance system for unmanned aerial vehicles with power industry applications. IET Radar Sonar Navig. 2017, 11, 212-218. [CrossRef]

68. Ha, H.; Han, S.; Lee, J. Fault Detection on Transmission Lines Using a Microphone Array and an Infrared Thermal Imaging Camera. IEEE Trans. Instrum. Meas. 2012, 61, 267-275. [CrossRef]

69. Sudevalayam, S.; Kulkarni, P. Energy Harvesting Sensor Nodes: Survey and Implications. IEEE Commun. Surv. Tutor. 2011, 13, 443-461. [CrossRef]

70. Cetinkaya, O.; Akan, O.B. Electric-Field Energy Harvesting in Wireless Networks. IEEE Wirel. Commun. 2017, 24, 34-41. [CrossRef]

71. Menendez, O.A.; Perez, M.; Cheein, F.A.A. Vision based inspection of transmission lines using unmanned aerial vehicles. In Proceedings of the 2016 IEEE International Conference on Multisensor Fusion and Integration for Intelligent Systems (MFI), Baden-Baden, Germany, 19-21 September 2016; pp. 412-417. [CrossRef]

(C) 2019 by the authors. Licensee MDPI, Basel, Switzerland. This article is an open access article distributed under the terms and conditions of the Creative Commons Attribution (CC BY) license (http:/ / creativecommons.org/licenses/by/4.0/). 